\title{
Study on the Legal Issues in Transfer of Personal Online Stores
}

\author{
Yong Liu \\ School of Arts and Law \\ Wuhan University of Technology \\ Wuhan, China
}

\begin{abstract}
With the rapid development of the Internet technology, online shopping has become a lifestyle for Chinese people. The growing number of online shoppers has led to the rise in number and size of online stores. Owners of personal online stores register personal online stores by entering into a service agreement with online service platforms. In the process of operation, owners of online stores need to transfer their personal online stores for various objective reasons. The actual demand for such transfer is enormous, but the user agreement of online services platforms prohibits such transfers. The original store owner can only transfer in private, but such transfer cannot change the real name information, and has caused a series of disputes. Through the legal regulation on the transfer of personal online stores, it can protect the legitimate rights and interests of online store owners and consumers, and promote the vigorous development of the Internet economy.
\end{abstract}

Keywords—personal online store; virtual property; transfer

\section{INTRODUCTION}

With the development of the Internet in China, transactions based on Internet E-commerce platforms have rapidly sprung up. Taking Taobao as an example, sales volume on " 12.12 " in 2017 reached 168.2 billion yuan. With the rapid development of the Internet economy, online stores that take cyberspace as a carrier have grown rapidly in both quantity and scale. A large number of online stores will inevitably lead to the transition from the old to the new stores. Some online store owners need to transfer their own stores for various reasons such as operation and life. Most Ecommerce platforms, such as Taobao, prohibit the private agreement on transfer of online stores. This causes the agreement on transfer of online stores to fail to change the store's identity registration information. The transferor of the online store can retrieve the online store through the identity information, and then the transferee can only defend the rights by suing the transferor for breach of contract. In the long run, there will inevitably be a lot of disputes. In addition, since the store is transferred in private, the buyer cannot know the store transfer information, which damages the consumers' right to know, and is not conducive to the healthy development of E-commerce.

The so-called online store is a store established by a natural person, legal person, or other organization in the virtual website environment based on the purpose of selling goods and services, which is reviewed and approved by the relevant Internet service provider. According to the different identities of the online store transaction objects, online stores can be divided into three modes: The first is B2B mode, that is, the enterprises conduct online transactions through data messages. The second is $\mathrm{B} 2 \mathrm{C}$ mode, which is an online transaction mode between enterprise and individuals. The third is $\mathrm{C} 2 \mathrm{C}$ mode, which is an online goods and services transaction between individuals through data messages, relying on the transaction platform. The "personal online store" that I refer to here is the carrier established by individuals to sell goods and services under the third mode. Such online stores are established by natural person, individual partnership or an individual business that has not obtained industrial and commercial registration for the purpose of conducting online transactions on the network transaction platform provided by a third party, with personal real name information tied.[1] Personal online stores are different from personal online store operators, and the latter refers to the natural persons, individual partnership or individual business that register and operate personal online stores on the network transaction platform. Personal online store operators and personal online stores have close ties but are very different. They are often confused in theory and practice, so I will compare them here. (1) Different scopes: personal online store operators include natural persons, individual partnership or individual business, while personal online stores are the products registered by these entities on the network transaction platform; (2) Different natures: personal online store operators are natural persons or aggregations that can independently assume civil rights and obligations according to law, while personal online stores are generally considered not to have the ability to independently assume civil rights and obligations; (3) Different independence: personal online store operators have independent consciousness and can independently express their meanings, while personal online stores are highly dependent and require the help of their operators to complete specific transactions. 


\section{PROBlems IN THE TRANSFER OF PERSONAL ONLINE} STORES

\section{A. Prohibition by Format Term Agreement}

The establishment of a personal online store requires the online store owner to sign a user agreement with the network service providing platform. Such agreement is generally a format contract produced by the network service provider. The store owner can only successfully register the platform account and become a platform user after agreeing to the user agreement. Since the transfer of personal online stores is still blank in law, the agreement between the owner of the online store and the provider of the network platform becomes a norm that constrains the behavior of both parties. Unfortunately, the principle of service agreement prohibits the transfer of personal online stores. Taking the user agreement of Taobao as an example, the user agreement stipulates that "since the user account is associated with the user's credit information, you can transfer the account only when there is an express term in law, judicial ruling or Taobao's agreement, it conforms to the user account transfer process stipulated by Taobao's platform rules. Once your account is transferred, the rights and obligations under the account will be transferred together. Except for the above situations, your account cannot be transferred used in any way, otherwise Taobao platform has the right to affix your breach of contract, and all responsibility arising therefrom is borne by you."

\section{B. Complex Composition of Personal Online Store Assets}

A great difficulty in the transfer process of personal online stores is how to value the asset of online stores. Due to the virtual nature of personal online stores, the asset value of the stores assets presents ambiguity and diversity. In practice, there are three main difficulties in dealing with the value of personal online store assets: (1) Assessment of tangible assets. This is mainly because most personal online stores do not have business registration, tax records or visual asset records such as storefronts, and lack professional accounting management, so it is difficult to assess the tangible assets of personal stores. (2) Assessment of expected incomes. Expected income is a reference for the future development prospects of personal online stores, and has important assessment significance for the value of stores. However, the expected income is uncertain, and personal online stores are in a rapidly changing network environment, making it difficult to conduct professional evaluation. (3) Assessment of credit assets. For personal online stores, the favorable rate of buyers is a key factor affecting their income. Although the network service platforms have established a set of credit rating mechanisms, how to equate the level to value is very controversial in practice. In short, there is a lack of a unified and effective assessment mechanism for the value of personal online store assets in reality. [2]

\section{Credit Crisis in Transfer of Personal Online Stores}

The credit of a personal online store is the result of longterm honesty management of the store owner, which includes the consumers' trust in the store owner and the friendship between them. The credit of the store owner has a huge impact on transaction security and satisfaction. However, due to the virtual nature of personal online stores, consumers cannot intuitively discover that the online store has been transferred. The credit relationship established over a long time will be affected by the change of the online store owner, and the new store owner may not meet consumer expectations that have long been formed. Taobao prohibits the free transfer of personal online stores with some considerations based on such factors, too.

\section{LEGAl AtTRIBUte ANALYSIS ON PERSONAL ONLINE STORES}

In order to effectively solve the problem of personal online store transfer, it is necessary to clarify its nature, regarding the attribute of personal online stores; the theoretical circles mainly have disputes in "subject theory" and "object theory". Scholars who hold the "subject theory" think that personal online store is a commercial subject or an ordinary civil subject. In the view that the personal online store is a commercial subject, there are arguments of "individual sole proprietorship", "individual business" and "commercial partnership". Among the scholars who hold the "object theory", there is also much controversy about what right object the personal online store is, and a representative viewpoint is the "virtual property theory".

The so-called object refers to the object to which the subject's rights and obligations point. [3] The virtual property theory is representative among object theories, that is, personal online store should be considered as a virtual property. [4] According to Article 127 of the General Principles of the Civil Law: "If the law has provisions on the protection of data and network virtual property, implement according to its provisions". According to the system interpretation method, virtual property obviously belongs to the category of civil objects; according to the virtual and property characteristics of personal online stores as described above, scholars identify personal online stores as virtual property.

However, "virtual property" itself is not a very certain concept. The main controversies in the theoretical circles are "credit theory", "property right theory" and "intellectual property theory". After comparing the definitions of many scholars, Dr. Qu Lingmin defines "virtual property" as: virtual property (item) refers to the simulation of items in the real world or phenomenon that is recorded in the form of data code, stored in the virtual space and digitally presented in the network environment, including network accounts and virtual items in the network account. [5] Under this definition, personal online stores are clearly classified as virtual property.

Article 127 of the General Principles of Civil Law newly promulgated by China stipulates: "If the law has provisions on the protection of data and online virtual property, implement in accordance with its provisions". Although this article does not clarify the debate on the nature of virtual property in theory and practice, it clarifies the property attribute of data and online virtual property, which is the first 
step to protect virtual property. Personal online stores have four attributes of property: 1. Value: it can meet people's needs; 2. Scarcity: it is not unlimited; 3. Independence: it is outside the human body; 4 . Can be dominated by manpower. [6] Besides, personal online store is simulation of items in the real world or phenomenon that is recorded in the form of data code, stored in the virtual space and digitally presented in the network environment, which further proves that it is a virtual property. Finally, in the context of the transfer of personal online stores, the identification of personal online stores as virtual property is conducive to the construction of transfer mechanisms and rules.

\section{Personal Online Store Operators Have Rights TO ONLINE STORES}

On the basis of the "virtual property theory", there are mainly arguments of property rights and credits in terms of the nature of virtual property. Scholars who hold "credit theory" believe that the legal attribute of virtual property is actually a contractual obligation confirmed through network agreement, but such credit has some attributes of property right. Scholars who hold this view believe that the theory of property right cannot explain the fact the personal online stores need the cooperation of the operating platforms to exercise their rights, and that personal online stores are second-level domain names generated based on network protocols, which are owned by the platform and do not have property rights exclusiveness, so personal online stores is the object of debt but not the object of the property rights. The rights enjoyed by the owner of online stores are only the contractual obligation arising from bestowal or lease. The "theory of property right" is mainly from the perspectives of tangible and intangible assets such as credits and resources accumulated by the stores, which are all obtained by personal online shop operators based on their business operations and should be exclusive to the personal online store owners.

Regarding the ownership of personal online stores, it should be discussed from the formation process of online stores. Personal online stores are based on the first-level domain name carried by the network platform provider, and the second-level domain names are generated after users' registration application. Then the users conduct long-term operations and gradually form business assets such as customer groups and credits. Obviously, the first-level domain name belongs to the network platform provider. The second-level domain names are built on the basis of the firstlevel domain name, and should also belong to the network platform provider, because these domain names are the products of the labor paid by the platform provider. As far as the domain name is concerned, its ownership is not transferred due to the user's use. As for what rights the user has to the second-level domain name, the content of the user agreement should be referred to. As for whether the user agreement is reasonable and what type of contract this user agreement belongs to are not discussed here. Forcibly interpreting the personal online store as the "object" in the Property Law does not conform to the spirit of the property rights law.
The electronic business asset is an intangible business asset with data existence as the basic form owned by enterprises through E-commerce operation on the network platform. Such assets include tangible and intangible assets such as credit ratings and customer base of online stores. Although these assets are the result of years of hard work by online store operators, and are closely related to the work of online store owners, the attributes of these assets are greatly different. First of all, in my opinion, as the a factor greatly affecting the operating income, online store credit rating, which is an intangible asset, belongs to the content under the contract, and should be the same as the online store domain name, which belongs to the contractual obligation. Taking Taobao as an example, Taobao's user agreement contains a lot of content in terms of user credit rating, and the credit rating mechanism of personal online stores is established through agreement. Therefore, the credit rating of this intangible asset should belong to the contractual obligation. Beyond that, other assets of the personal online store should belong to the operator, including tangible assets such as goods in the online store, and intangible assets such as the customer base of the merchant. The essence of these business assets is the income generated by the operators based on the user agreement by exerting their personal abilities. However, it cannot draw a conclusion that the personal online store belongs to the user exclusively, but should distinguish such income from contractual obligation that brings the income.

In summary, the rights enjoyed by personal online store operators are essentially special contractual obligations based on user agreements. The business assets generated in addition to the credit of the online store are actually the income brought by the efforts of the operators based on such obligation.

\section{CONCLUSION AND SUGGESTION}

\section{A. Establishing Virtual Property and Credit Assessment Mechanism}

Establish a specialized assessing agency and uniform industry standard for personal online stores. With the further development of the Internet, the transaction demand for virtual property is bound to increase. China's current property mechanism is increasingly unable to meet this demand. To this end, a set of unified virtual property assessment mechanisms needs to be established. In addition, since each network transaction platform has its own independent credit rating rules, it will inevitably cause misunderstanding in credit assessment, which is not conducive to the assessment at the time of online store transfer, so it is necessary to make appropriate adjustments to the credit assessment mechanism.

\section{B. Improving Safeguard Measures After Transfer}

The transfer of personal online stores allows new store owners to replace the status of old store owners to operate. In order to fully protect the legitimate rights and interests of consumers and promote the healthy development of Ecommerce, various measures should be taken to ensure the 
quality of goods and services after transfer. Firstly, after the transfer of a personal store, the new store owner of the store should make a public announcement. Since the transfer of online store is carried out online, consumers are not aware of the transfer. To protect the consumers' right to know, a certain publicity period can be set, and the new store owner is required to publicize the store transfer on the store's homepage. In addition, the platform can ask the new store owner to pay deposit and promise a period for return of goods without reason within seven days, so as to protect the consumers' rights and prevent the new store owner from using the store's credit and flow to do whatever he/she wants.

\section{Conclusion}

Personal online store is a contractual obligation of the store owner based on the service agreement, whose transfer requires the platform to agree. However, service platforms should not use their dominant position to prohibit the transfer of stores when the store owner is unable or unwilling to operate. Such format contract is unreasonable and unfair and needs to be corrected. In the context of the market economy, the demand for the transfer of personal online stores should be guided, and a reasonable operating mechanism should be provided, rather than blindly prohibited. For the Internet as a new thing, the lag of the law is inevitable, but in the face of problems, it is the attitude that the law should have to respond positively and keep pace with the times.

\section{REFERENCES}

[1] Zhang Rongzhen. Study on Transfer and Inheritance of Personal Online Stores under C2C Transaction Mode [D]. Chongqing: Law School, Southwest University, 2014. (in Chinese)

[2] Liu Ting. Study on the Legal Issues of Online Store Segmentation in Divorce Cases under the Background of the Internet Age [J]. Journal of Law Application, 2016, (1). (in Chinese)

[3] Wei Zhenyin. Civil Law. Beijing: Peking University Press, Higher Education Press, 2007. (in Chinese)

[4] Shen Danfeng. Study on the Legal Issues in Transfer of Operation Rights of Personal Online Stores [D]. Hangzhou: Master's thesis of Zhejiang University, 2014. (in Chinese)

[5] Qu Lingmin. Conceptual Consensus and Legal Attributes of Virtual Property [D]. Shandong: Law School, Shandong University, 2017. (in Chinese)

[6] Yang Lixin, Wang Zhonghe. On the Property Right Attribution of Network Virtual Property and Its Basic Rules [D] Beijing: Law School, Renmin University of China, 2004. (in Chinese) 